\title{
Combining the Theory of Designing Landscape Sculpture and Computer Aided Technology on the Landscape Sculpture
}

\author{
Dawei Pang ${ }^{1,2, *}$ and Evariste ${ }^{2}$ \\ ${ }^{1}$ College of Material Science and Art Design, Inner Mongolia Agricultural University, Huhehaote 010018, China \\ ${ }^{2}$ University Marc Bloch-Strasbourg, France
}

\begin{abstract}
With the rapid development of computer technology, its application is also becoming wider. At present, the wide application of computer technology in the design of landscape sculpture considerably transfers the traditional one, which improves the progress and development of modern landscape sculpture design. Meanwhile, the computer technology also provides designer more forms of creation and offers better development space which is conducive to the new artistic work. Compared to the traditional design procedures, the design of landscape sculpture by the computer technology has many advantages. The traditional one with the use of pen and paper would waste time and cannot give visual effect during the research and design of the sketch. However, the computer can realize any ideas of the designer, and further modify according to the new requirements with fewer time. With the application of computer, the design sketch is not limited in a flat paper anymore and can be more vivid in a comprehensive and full-view three-dimensional one. This research mainly introduces the basic theory of the landscape sculpture and the research and design of landscape sculpture combining computer technology, which provides designer more convenient forms of creation. The application of computer technology considerably enhances the success rate of the engineering and perfects the design which cut down the time of the whole creation of landscape sculpture.
\end{abstract}

Keywords: Landscape sculpture, computer technology, assisted combination.

\section{INTRODUCTION}

Now, the development of computer technology is very fast, and the society has also entered into informational era, network era and digital era which gives people more happiness. The perfect combination of science and technology further improves our life and makes the boundary of them vaguer which puts the sense of beauty of the art into the design of software and interfaces of computer and also puts the efficiency and convenience of computer into the development and creation of art. Now, the computer aided technology is playing an important role in so many fields, such as film and television, animation and landscape sculpture etc. It also gradually permeates and innovates in the field of landscape sculpture. The application of computer aided technology makes the former complex procedure more flexible and provides designer more new forms of creation and methods to quickly realize the ideal model. For example, the Fig. (1) is a general model of design of landscape sculpture, the computer also need people rather than replace people's brain and requires the field visit and other work. So the designer of landscape sculpture must know the theory of creation of landscape sculpture and expertly apply the relevant software. They should adequately combine the theory and the technology to offer new energy to modern creation of landscape sculpture and helps the designer to create better work.

The application of computer aided technology transfers the traditional way of drawing. Computer aided technology offers a more exact design model and a three-dimensional effect picture which can be understood by audience. The traditional one is comparatively complex and wastes time and energy which only completed by the designer by hand and cannot be modified. However, the application of computer aided technology has advantages such as high efficiency, easily-modify and so on. It can realize three-dimensional effect picture which is flexible and comprehensive.

\section{THEORY OF DESIGNING LANDSCAPE SCULPTURE AND COMPUTER AIDED TECH- NOLOGY}

The work of landscape sculpture is not only come from designer's heart but also reflects the idea of life and aesthetic taste of modern people. Every creation of landscape sculpture pays great attention to the selecting topic, form, shape, and color which requires the professional knowledge of landscape sculpture. The application of computer makes the modification of the drawing of landscape sculpture design easier and transfers the static effect picture into dynamic three-dimensional effect picture which costs less and have high efficiency. 


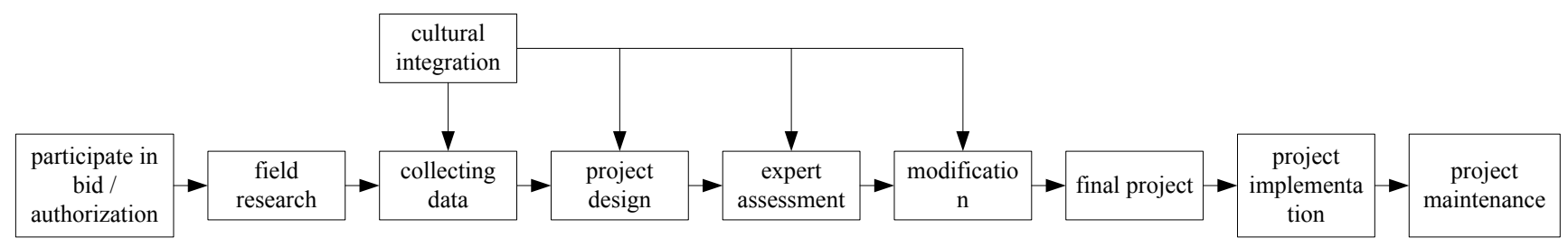

Fig. (1). The general model of design of landscape sculpture.

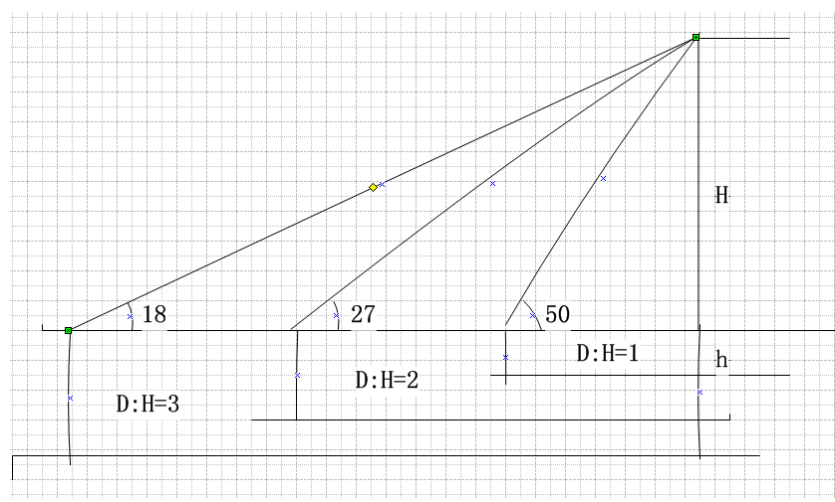

Fig. (2). The proportion of size of landscape sculpture and the space.

\subsection{The Theory of Landscape Sculpture}

The perfect combination of landscape and sculpture not only adds beauty and specialness of landscape into sculpture but also its diversified forms and artistry. In the other European countries, the name of landscape sculpture is different. In China, we can also call it urban sculpture which mainly treats landscape as a platform and builds a sculpture in a public place and shows common people a modern art and enhance the sense of beauty of the city setting off the spirit and environment of the city.

Landscape sculpture is a subject which comparatively covers more fields. So only mastering good theory can one create a work which has representativeness and aesthetic nature. Most of the landscape sculptures are built in a public place outside of the building. So they should be combined with the outside circumstances. And it is impossible to create work before searching for a suitable environment. Therefore, it is essential to combine the landscape sculpture work and the geographic position and to realize the unification and coordination. The proportion of size of landscape sculpture and the space is shown as Fig. (2).

The style of the landscape sculpture should also be considered and the size of the landscape sculpture should be suited to the whole size of the space rather than designing it according to the size of the plane. It also needs that the artist thinks over again and again to gain perfect effects. Of course, the rule can be changed according to the practical conditions. The size of the landscape sculpture and the whole environment should give a balanced view which cannot be limited in a plane design of drawing nor neglect the sculpture itself. The designer should consider the comfort of the looker to determine the size of sculpture human-friendly shown in Table 1 which analyzes the proportion of sculpture in Fig. (2).

Table 1. The analysis of the proportion of the size of sculpture.

\begin{tabular}{|c|c|}
\hline D: $\mathbf{H}<\mathbf{1}$ & $\begin{array}{c}\text { The details of the bottom of sculpture can be easily } \\
\text { seen which will provide a sense of pressure to observer }\end{array}$ \\
\hline \hline D:H $=1$ & Exactly seeing the whole sculpture. \\
\hline $\mathrm{D}: \mathrm{H}=2$ & Compact effect of sculpture is a good view. \\
\hline $\mathrm{D}: \mathrm{H}=3$ & $\begin{array}{c}\text { Better seeing the whole sculpture and the visual spaces is } \\
\text { more relaxed. }\end{array}$ \\
\hline
\end{tabular}

Besides, the content and the theme of landscape sculpture should be coordinated with the practical environment and the modeling also should be considered. The material of the sculpture should be integrated into the surrounding environment, and the color should embellish the environment. And of course, the most important point is that the theme of the sculpture cannot contradict the environmental background or the other problem such as culture. In the picture, the Danish Sculpture of Mermaid [2] is not only an article work, but also links with the history and culture. This sculpture's main idea is based on the story of Daughter of the Sea from the original work of Andersen which is perfectly combined with the surroundings. So it gives visitor profound impression and becomes a representative landscape mark. 
The success of a sculpture not only depends on the idea of the designer but on his/her original intention, on whether service for citizens, on whether the society needs this guide. Shenzhen is a leading city in China's reform and opening up which possesses the spirits of struggle and innovation. Located in the square of Shenzhen municipal government, the sculpture of Pioneer [3] shows a strong running bull whose strength seems to pull a tree up by the roots. This sculpture adopts vivid true-life method which explains a new Shenzhen putting away the old ideas.

\subsection{Computer Aided Technology}

The computer aided technology refers to realize the establishment and design of model by using the powerful computing and graphics capability under the operation of people. Computer Aided Design (or CAD) combines the knowledge of computer and requirements of the engineering design to form a new field of application and development of computer which helps user easily design the model or modify and analyze the model. In recent years, the application of computer aided technology gradually changes the development patterns in each field and powerfully impacts the traditional production mode and pushes them to learn new technology to adapt to the development of the era. It also accelerates the development and reform of the era and brings more benefits and influences to people.

Now, the level of computer aided technology is an important indicator to measure integrated design level of a nation. The computer aided technology has permeated each field especially the manufacturing industry, the design of electronic circuit, and the design of landscape sculpture etc.

\section{THE DESIGN AND RESEARCH OF THE LANDSCAPE SCULPTURE COMBINING COM- PUTER TECHNOLOGY}

Modern landscape sculpture design combining computer technology mainly uses graphic software as tool based on the design considerations of design of landscape sculpture which shows the idea by three-dimensional dynamic graph. It is essential to consider the geographic position and environment of the sculpture. And an excellent landscape sculpture could make the finishing point in the former environment.

An excellent landscape sculpture is not only limited to fill up the blank of the city but also can beautify the cultural environment of the city. The overall arrangement of the urban landscape can be divided into many forms which has linear and region and so on. But all of them need consider the local geographical conditions. For example, the sculpture of Spiral sloping breakwater [4-6] from Smith takes advantage of local geographical advantages and to transfer the space into a thin violet piece. This kind of description possessing poetry conveys the designer's love towards nature and adds a beautiful scenery line into the city.

\subsection{The Advantages of Landscape Sculpture Assisted by Computer}

With the rapid development of information era, each kinds of processing equipment have been improved in the terms of accuracy and efficiency. With the help of the computer technology, the design of landscape sculpture realized the perfect combination of theory and practice. The computer aided technology brings more benefits to the design of landscape sculpture and improves the transformation and progress of landscape sculpture.

The computer aided technology has high efficiency, so it can replace the traditional creative form of handwork. Besides, the computer aided technology can considerably decrease designer's complex and fragmentary work so that enhance the work efficiency and cut down the cycle of creation. The form of landscape sculpture also creates a new kind of communication mode and a medium of cultural transmission. There are many difficulties in traditional design of landscape sculpture, for example, repeating a model, changing an angle of sculpture, zooming the size of model and so on. However, all of these problems can be solved by the computer technology. As the internet rapidly develops, several computers can be used simultaneously during designing the landscape sculpture. This considerably changes the former working and increases the efficiency so as to adapt to the quick era.

Computer aided technology has high accuracy and the computer can trace out the idea of the designer according to his or her design. Being diverse from the manmade work, as long as the designer's parameter and other configurations are not wrong in advance, the computer can be accurate after a few of the decimal point. With the help of the computer aided technology, the parametric modeling can be realized which would brings more convenience to the designer of landscape sculpture.

Computer aided technology has high visual reliability which can provide the designer so many colors and material. In this way, during the creation, the designer can choose optionally and make the work more vivid. The effect of threedimensional stereogram can comprehensively analyze the work looks like a true sculpture which can motivate the designer's inspiration. Adding the sound and practical simulated diagram, the computer technology can provide a vivid design process which can realize the cooperation between people and computer.

\subsection{The Analysis of the Design Procedure of Landscape Sculpture Aided by Computer}

The traditional design procedure of landscape sculpture is very complex requiring much human resources and material resources. But the design of landscape sculpture aided by computer just needs one tool that could complete the drawing and rebuild. As for some complex model which would gradual change, the computer only need to do a simple work. The computer can also realize the zoom and copy of the size of the model and create effect pictures with different colors and choose the best model. The Fig. (3) is a flow chart of first draft of traditional landscape sculpture design.

The library of the computer software 3DMAX [9] possesses many material which the designer can randomly choose and make the sculpture more vivid. With the powerful memory function of computer, each step would be recorded which is convenient for modification and the final 


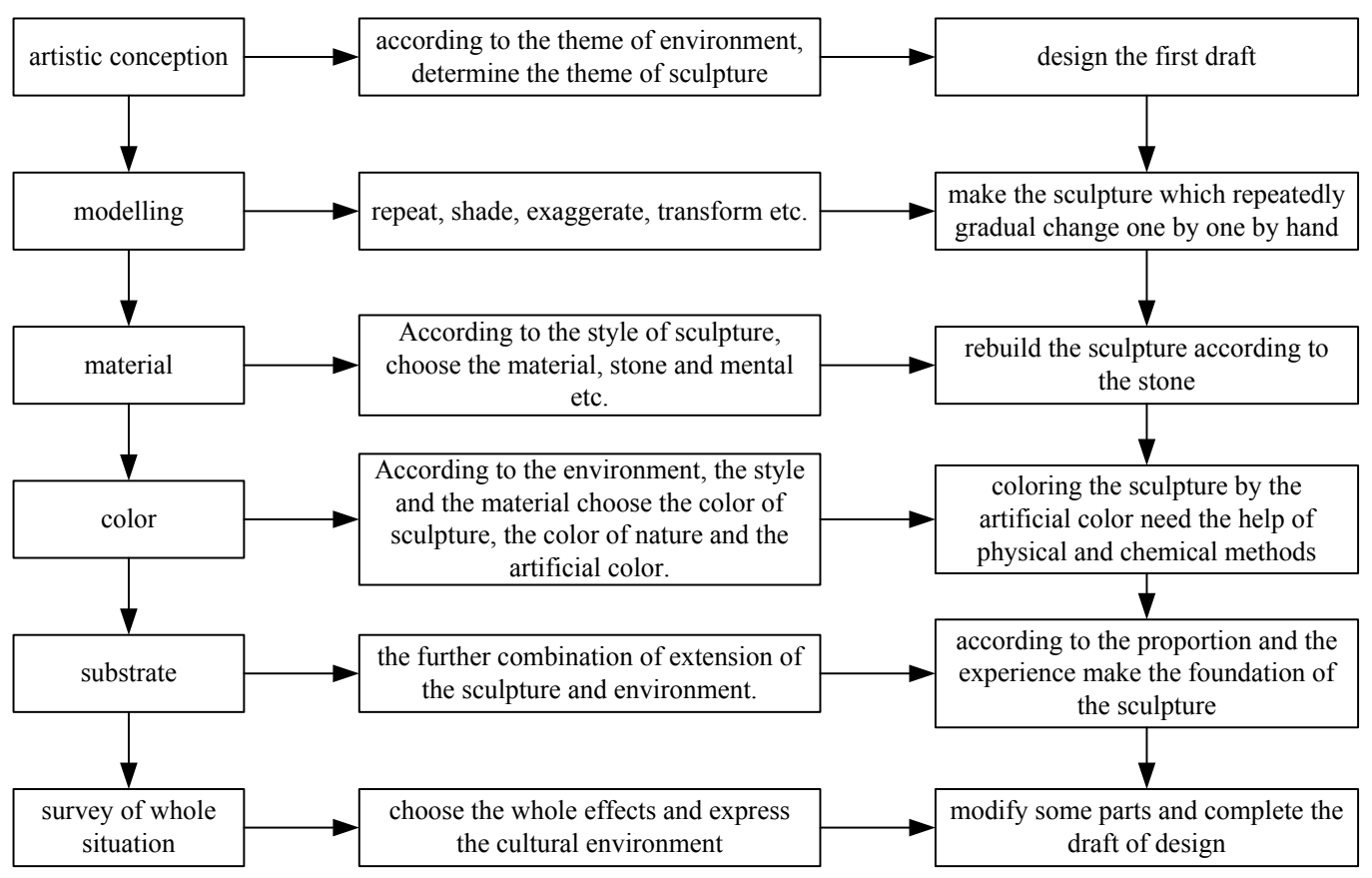

Fig. (3). Flow chart of first draft of traditional landscape sculpture design.

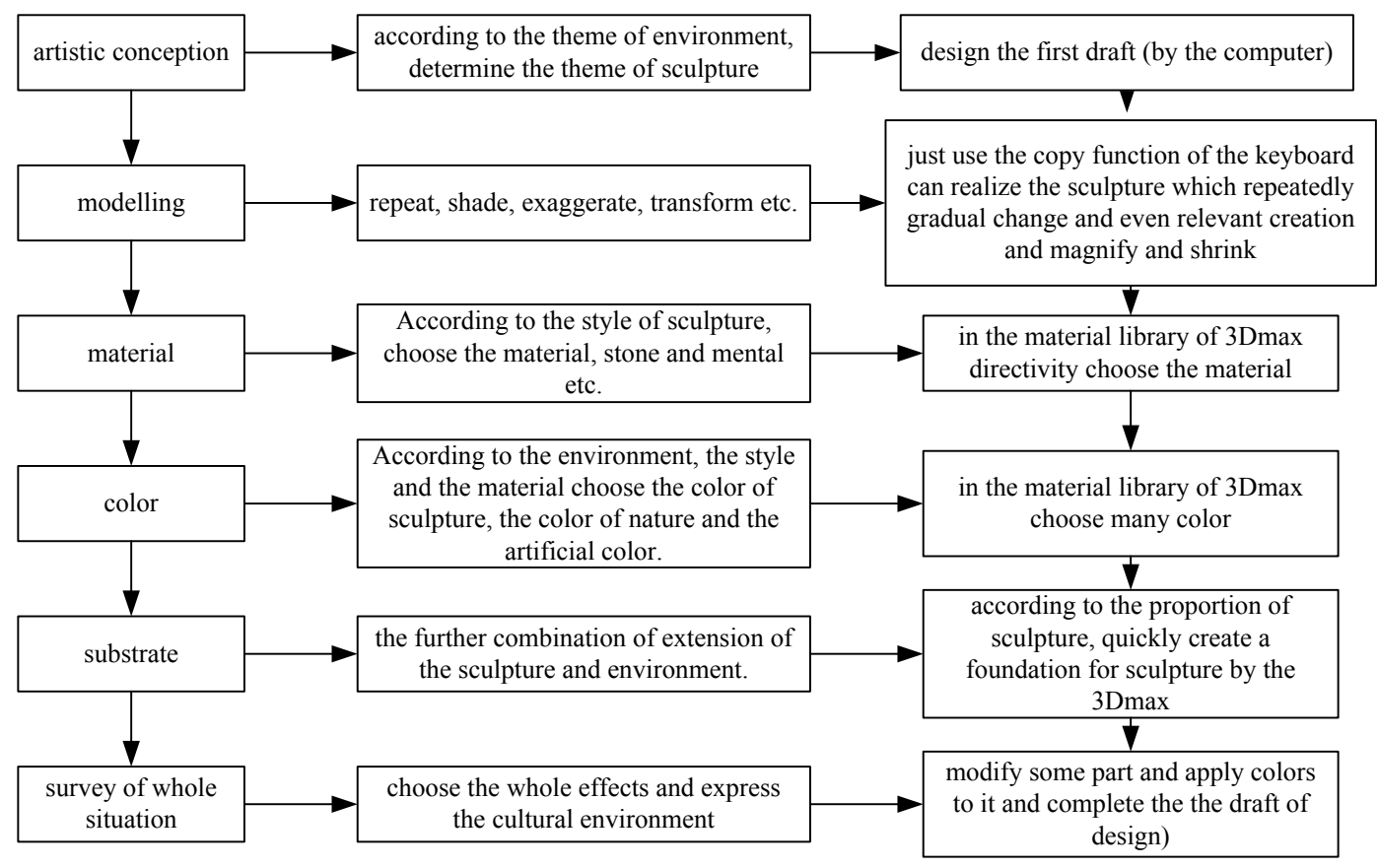

Fig. (4). Flow chart of first draft of modern landscape sculpture design.

work. For example, the Fig. (4) is the flow chart of first draft of modern landscape sculpture design.

\section{CONCLUSION}

With the changes of people's life, the computer aided technology also gradually changes the development and creative form of the landscape sculpture. Everyone pursue the beauty, and the application of computer technology helps the designer show the beauty of the sculpture and creates a better work. The computer technology considerably solves problems about the contradictions between the sculpture and surroundings and improves the realization and implementation of the design of the landscape sculpture. Meanwhile with the help of the computer, the design saves more time and money and brings more humanized life space. 


\section{CONFLICT OF INTEREST}

The authors confirm that this article content has no conflict of interest.

\section{ACKNOWLEDGEMENTS}

Declared none.

\section{REFERENCES}

[1] K. Hou, "Applied research on the landscape sculpture plan aided by computer", Zhengzhou University, 2013

[2] L. Su and W. L. Wang, "The design of landscape sculpture in the urban street a study of design of landscape sculpture in the HaiLian road in Lianyungang (in Jiangsu Province)", Journal of Chifeng University (Natural Science Edition), vol. 6, pp. 49-50, 2013.

[3] L. Su and W. L. Wang, "The research and analysis on the design of public landscape architecture sculpture a study of the sculpture park of Wuhu Municipality', Journal of Chifeng University (Natural Science Edition), vol. 7, pp. 64-65, 2013.

[4] L. Su and W. L. Wang, "The application and analysis of design of the landscape sculpture in the urban squarea study of design of landscape sculpture in the urban square in Lianyungang (in Jiangsu Province)", Art Research, vol. 2, pp. 14-15, 2013.

[5] Z. L. Liu, "Fractal theory and application in city size distribution", Information Technology Journals, vol. 12, no. 17, pp. 4158-4162, 2013. doi:10.3923/itj.2013.4158.4162

[6] H. H. Zhao, "The research on the application of the computer aided design in the teaching of artistic designing", Journal of TaiYuan Urban Vocational College, vol. 8, pp. 46-48, 2012.

[7] X. C. Fu, "The research on the application of computer aided design in showing the landscape", Northwest Agriculture \& Forestry University, 2010.

[8] Y. Q. Deng and J. X. Zhou, "The application of system thinking in the design of landscape sculpture", Art and Education, vol. 1, pp. 148-149, 2011.

[9] W. H. Zhou and H Lan, "The research and development of designing product assisted by computer", The conference proceedings of 2005 International Industrial Design, 2005

(C) Pang and Evariste; Licensee Bentham Open.

This is an open access article licensed under the terms of the Creative Commons Attribution Non-Commercial License (http://creativecommons.org/licenses/by-nc/3.0/) which permits unrestricted, non-commercial use, distribution and reproduction in any medium, provided the work is properly cited. 